\title{
High Survivorship With Cementless Stems and Cortical Strut Allografts for Large Femoral Bone Defects in Revision THA
}

\author{
Young-Hoo Kim MD, Jang-Won Park MD, Jun-Shik Kim MD, \\ Devarshi Rastogi MD
}

Received: 7 January 2015/Accepted: 13 May 2015/Published online: 27 May 2015

(C) The Association of Bone and Joint Surgeons(B 2015

\begin{abstract}
Background Numerous studies have investigated the clinical and radiographic results of revision THAs with use of cementless stems and cortical strut allografts. However, to our knowledge, no long-term followup studies have evaluated patients undergoing revision THA with use of cortical strut allografts where the allografts provided the primary stability for extensively coated femoral stems in the presence of extensive femoral diaphyseal bone defects. Question/purposes We performed this study to determine (1) validated outcomes scores; (2) radiographic signs of fixation and allograft healing; (3) frequency of complications; and (4) survivorship of the components after use of cortical strut onlay allografts in Types IIIB and IV femoral diaphyseal bone defects.
\end{abstract}

Each author certifies that he or she, or a member of his or her immediate family, has no funding or commercial association (eg, consultancies, stock ownership, equity interest, patent/licensing arrangements, etc) that might pose a conflict of interest in connection with the submitted article.

All ICMJE Conflict of Interest Forms for authors and Clinical Orthopaedics and Related Research ${ }^{\mathbb{R}}$ editors and board members are on file with the publication and can be viewed on request.

Clinical Orthopaedics and Related Research ${ }^{\mathbb{B}}$ neither advocates nor endorses the use of any treatment, drug, or device. Readers are encouraged to always seek additional information, including FDAapproval status, of any drug or device prior to clinical use. Each author certifies that his or her institution approved the human protocol for this investigation, that all investigations were conducted in conformity with ethical principles of research, and that informed consent for participation in the study was obtained.

Y.-H. Kim ( $₫)$, J.-W. Park, J.-S. Kim, D. Rastogi

The Joint Replacement Center, MokDong Hospital, Ewha

Womans University School of Medicine, 911-1 MokDong,

YangChun-Ku, Seoul 158-710, Republic of Korea

e-mail: younghookim@ewha.ac.kr
Methods Between 1994 and 2003, we performed 140 revision THAs in 130 patients with Paprosky Types IIIB and IV femoral diaphyseal defects. The patients were treated using extensively coated femoral stems and cortical strut allografts because primary axial or rotational stability could not be achieved without grafting. Ten of the patients (10 hips; 7.7\%) were lost to followup or died before 10 years; the remaining 120 patients (130 hips) represent the study group in this retrospective study. There were 66 men and 54 women. Their mean age at the time of index surgery was $59 \pm 18$ years (range, 36-67 years). The primary diagnosis was predominantly osteonecrosis of the femoral head $(53 \%)$. The most common reason for revision was aseptic loosening (97\%), followed by periprosthetic fracture (3\%). The mean time from primary to revision THA was 12 years (range, 8-27 years). The mean duration of followup was 16.1 years (range, 12-20 years).

Results The mean Harris hip score was $39 \pm 10$ points before revision and improved to $86 \pm 14$ points at 16 years followup $(\mathrm{p}=0.02)$. The mean preoperative WOMAC score was $62 \pm 29$ (41-91) points and improved to $22 \pm 19(11-51)$ points at 16 years followup $(\mathrm{p}=0.003)$. Of the 130 stems, 113 (87\%) had bone ingrowth, five (4\%) had stable fibrous ingrowth, and $12(9 \%)$ were unstable. All allografts were incorporated. Four hips $(3 \%)$ had a displaced femoral shaft fracture at the stem tip; four (3\%) had a postoperative dislocation; and six (5\%) had early postoperative infection. Kaplan-Meier survivorship analysis, with revision or radiographic failure as the endpoint, revealed that the 16-year rate of survival of the components was $91 \%$ (95\% CI, 0.88\%-0.96\%).

Conclusion Supportive cortical strut onlay allografts provided high survivorship beyond 12 years of followup in revision THAs. Future studies might compare this 
approach with allograft-prosthesis composites, proximal femoral replacement, or modular fluted, tapered stems. Level of Evidence Level IV, therapeutic study.

\section{Introduction}

Revision of a failed THA is challenging because of the difficulty in obtaining and maintaining implant stability with poor bone quantity and quality [4]. Severe acetabular and femoral bone loss (Paprosky Types IIIB and IV) [28] can be seen in patients who have had multiple revision arthroplasties and in patients who have severe osteolysis. Large bulk allografts (such as proximal femoral allografts) or proximal femoral or total femoral replacement prostheses such as those used in tumor cases have been proposed as suitable reconstructive techniques for more severe femoral bone deficiencies [6, 9, 28, 29, 32, 33]. As an alternative, the use of structural cortical strut onlay allografts, in combination with cementless revision femoral stems, is a technique used for reconstruction of large femoral bone defects [3, 18, 23-25].

Successful results with cortical strut onlay allografts have been reported for Paprosky Type IIIA bone loss [18, 25-27] (severe femoral diaphyseal bone loss with less than $4 \mathrm{~cm}$ of intact cortical bone at isthmus). In these cases, tight press-fit fixation of the revision femoral stem was achieved in the femur before application of cortical strut onlay allografts. The application of cortical strut onlay allografts was intended to provide only supplementary augmentation of the femur $[9,18,27]$. However, to our knowledge, no previously published studies have explicitly reported on the long-term results of THAs, in which axial and torsional stability of the femoral stem was provided not by the host femoral bone, but by the cortical strut allografts in Types IIIB and IV femoral bone defects [27]. Since this is a technique we have used for femoral bone defects [3], we wished to evaluate the results at a minimum followup of 12 years.

The purpose of this study was to determine (1) validated outcome scores; (2) radiographic signs of fixation and allograft healing; (3) frequency of complications; and (4) survivorship of the components after use of cortical strut onlay allografts in Paprosky Types IIIB and IV femoral diaphyseal bone defects.

\section{Patients and Methods}

Between 1994 and 2003, we performed 140 revision THAs in 130 patients with Paprosky Types IIIB and IV femoral diaphyseal defects. The prerevision diagnoses were aseptic loosening in 136 hips (97\%) and periprosthetic fracture in four hips (3\%). The patients were treated using extensively coated femoral stems and cortical strut allografts because primary axial or rotational stability could not be achieved without grafting. We routinely used this approach in all patients who had no axial and torsional stability of the femoral stem provided by host femoral bone. Data for 130 patients were entered in the database. However, 10 of the 130 patients were later excluded from the database because they were lost to followup (seven patients) or died (three patients) before 2 years of followup. Therefore, 120 patients (130 hips) composed the study. The study was approved by the institutional review board, and all patients provided informed consent. Twenty of the 120 patients were reported in a previous study at a mean of 10 years of followup [23].

The study group included 66 men and 54 women who had a mean age $( \pm \mathrm{SD})$ of $59 \pm 18$ years (range, 3667 years) at the time of revision surgery. The mean height of the patients was $171 \pm 9 \mathrm{~cm}$ (range, $155-185 \mathrm{~cm}$ ), mean weight was $82 \pm 10 \mathrm{~kg}$ (range, $65-125 \mathrm{~kg}$ ), and mean BMI was $28 \pm 5 \mathrm{~kg} / \mathrm{m}^{2}$ (range, $27-37 \mathrm{~kg} / \mathrm{m}^{2}$ ). The minimum time from the primary to revision THA was 12 years (mean, 16 years; range, $8-27$ years). Seventy hips (54\%) had a Paprosky Type IIIB defect and $60(46 \%)$ had a Paprosky Type IV defect. Reasons for revision were aseptic loosening in 126 hips (97\%) and periprosthetic fracture in four hips $(3 \%)$. Thirteen hips $(10 \%)$ required one strut graft, 98 (75\%) required two strut grafts, and 19 $(15 \%)$ required three strut grafts. The minimum followup was 12 years (mean, (16 years; range, 12-20 years) (Table 1). The records of the 120 patients were entered in an ongoing computerized registry that was updated continuously. All of the hips were reviewed by a research associate (DRK) not involved with the revision surgery. Followups were scheduled at postoperative intervals of 3 months, 1 year, and yearly thereafter. At these intervals, the patients were evaluated and radiographs were obtained. Preoperative and postoperative review data were recorded according to the systems of Harris hip score [17] and WOMAC score [5]. Clinical, hematologic, and radiographic data were recorded, including any documented history of pyogenic or tuberculous infection at the site of a previous surgical procedure on the involved hip, relevant laboratory findings, and clinical features such as draining sinuses.

Seventy-nine hips (61\%) had a first revision surgery, 27 (21\%) had a second revision, $12(9 \%)$ had a third revision, and $12(9 \%)$ had a fourth revision. Although 79 hips had a first revision surgery, they had a significant femoral bone defect attributable to osteolysis and/or loosening. Bone defects were substantially worsened during removal of the cementless or cemented stems. There were no differences in bone defects between cementless and cemented stems. 
Table 1. Demographic data

\begin{tabular}{|c|c|}
\hline Parameters & Numbers \\
\hline Number of patients (hips) & $120(130)$ \\
\hline Male:female & $66: 54$ \\
\hline Age (years) (mean \pm SD [range]) & $59 \pm 18(36-67)$ \\
\hline Height $(\mathrm{cm})($ mean \pm SD [range] $)$ & $171 \pm 9(155-185)$ \\
\hline Weight $(\mathrm{kg})($ mean \pm SD [range]) & $82 \pm 10(65-125)$ \\
\hline $\mathrm{BMI}\left(\mathrm{kg} / \mathrm{m}^{2}\right)($ mean $\pm \mathrm{SD}$ [range] $)$ & $28 \pm 5(27-37)$ \\
\hline $\begin{array}{l}\text { Primary diagnosis (number [\%] of } \\
\text { patients/number of hips) }\end{array}$ & $13(52.5)$ \\
\hline Osteonecrosis of femoral head & $78(65) / 85$ \\
\hline Osteoarthritis & $30(25) / 32$ \\
\hline Traumatic arthritis & $6(5) / 6$ \\
\hline Multiple epiphyseal dysplasia & $6(5) / 7$ \\
\hline \multicolumn{2}{|l|}{ Type of bone defect (Paprosky [24]) } \\
\hline IIIB & 70 hips $(54 \%)$ \\
\hline IV & 60 hips $(46 \%)$ \\
\hline \multicolumn{2}{|l|}{ Reasons for revision (number of hips) } \\
\hline Aseptic loosening & $126(97 \%)$ \\
\hline Periprosthetic fracture & $4(3 \%)$ \\
\hline \multicolumn{2}{|l|}{ Number of revisions } \\
\hline First & 79 hips $(61 \%)$ \\
\hline Second & 27 hips $(21 \%)$ \\
\hline Third & 12 hips $(9 \%)$ \\
\hline Fourth & 12 hips $(9 \%)$ \\
\hline \multicolumn{2}{|l|}{ Number of strut grafts used } \\
\hline One & 13 hips $(10 \%)$ \\
\hline Two & 98 hips $(75 \%)$ \\
\hline Three & 19 hips $(15 \%)$ \\
\hline \multicolumn{2}{|l|}{$\begin{array}{l}\text { Zones of allograft (modified Gruen } \\
\text { zone [24]) }\end{array}$} \\
\hline 1 & Lateral proximal $1 / 3$ \\
\hline 2 & Lateral middle $1 / 3$ \\
\hline 3 & Lateral distal $1 / 3$ \\
\hline 4 & Around the stem tip \\
\hline 5 & Medial distal 1/3 \\
\hline 6 & Medial middle $1 / 3$ \\
\hline \multicolumn{2}{|l|}{ Grading of allograft resorption } \\
\hline Mild & $\begin{array}{l}<50 \% \text { of allograft thickness } \\
\text { in } 1 \text { or } 2 \text { zones }\end{array}$ \\
\hline Moderate & $\begin{array}{l}<50 \% \text { of thickness of } \\
\text { allograft in }>2 \text { zones } \\
\text { or }>50 \% \text { of thickness, but } \\
\text { not full } \\
\text { thickness in } 1 \text { or } 2 \text { zones }\end{array}$ \\
\hline Severe & $\begin{array}{l}\text { Full thickness in any zone } \\
\text { or }>50 \% \text { of the thickness } \\
\text { in }>2 \text { zones }\end{array}$ \\
\hline Followup (years) & $16.1(12-20)$ \\
\hline
\end{tabular}

The femoral components, which were in situ at the time of the current revision, were cementless femoral components in 107 hips (82\%) and cemented femoral components in 23 hips (18\%). The acetabular components, which were in situ at the time of the current revision, were cementless acetabular components in 114 hips $(88 \%)$ and cemented acetabular components in 16 hips $(12 \%)$.

\section{Surgical Technique}

It often was difficult to determine the severity of the bone loss from preoperative radiographs and CT scans; however, after implant removal, the available bone stock could be clearly defined by intraoperative findings. In all cases in the current series, bone loss was too severe (Paprosky defect Type IIIB or IV [27]) to provide satisfactory axial and torsional stability of a revision total hip prosthesis. The decision to use a cortical strut onlay allograft was made at surgery by a senior surgeon (YHK) if it was determined that axial and torsional stability of the trial femoral stem was not able to be obtained before application of the cortical strut onlay grafts. We never used other techniques such as circumferential proximal femoral allograft, impaction bone grafting, proximal femoral allograftprosthesis composite, proximal femur replacement and modular fluted tapered stem. Through a posterolateral approach, the acetabulum and the proximal $1 / 3$ of the femur were exposed. The loose femoral stem and acetabular component were removed. If the acetabular component was well fixed in an unsatisfactory position, a curved osteotome (DePuy, Warsaw, IN, USA) was used to remove the cup. An extended greater trochanteric osteotomy was performed in 81 hips $(62 \%)$ to remove the cementless or cemented stem with surrounding cement. Less than $2 \mathrm{~cm}$ of diaphyseal-isthmic bone was available after removal of the stems in all hips.

All patients had implantation of fresh-frozen femoral cortical strut onlay allografts (LifeNet Health, Virginia Beach, VA, USA). One cortical strut allograft was used when one side of the femur had a bone defect, two were used when two sides of the femur had bone defects, and three were used when three sides of the femur had bone defects. One cortical strut onlay allograft was used in 13 hips (10\%), two were used in 98 hips $(75 \%)$, and three were used in 19 hips (15\%).

The width and length of the cortical strut onlay allografts were selected to bridge the bone defects without interfering with the knee. Proximally, impingement of the strut onlay grafts against the pelvis was avoided. The mean width of the individual strut graft was $4 \mathrm{~cm}$ (range, 3$6 \mathrm{~cm}$ ), and the mean length was $25 \mathrm{~cm}$ (range, 16-32 cm). To maintain femoral blood supply, only limited dissection of the soft tissues from the femur, especially at the linea aspera, was done. If possible, the remaining periosteum and residual shells of host bone were left in place. 

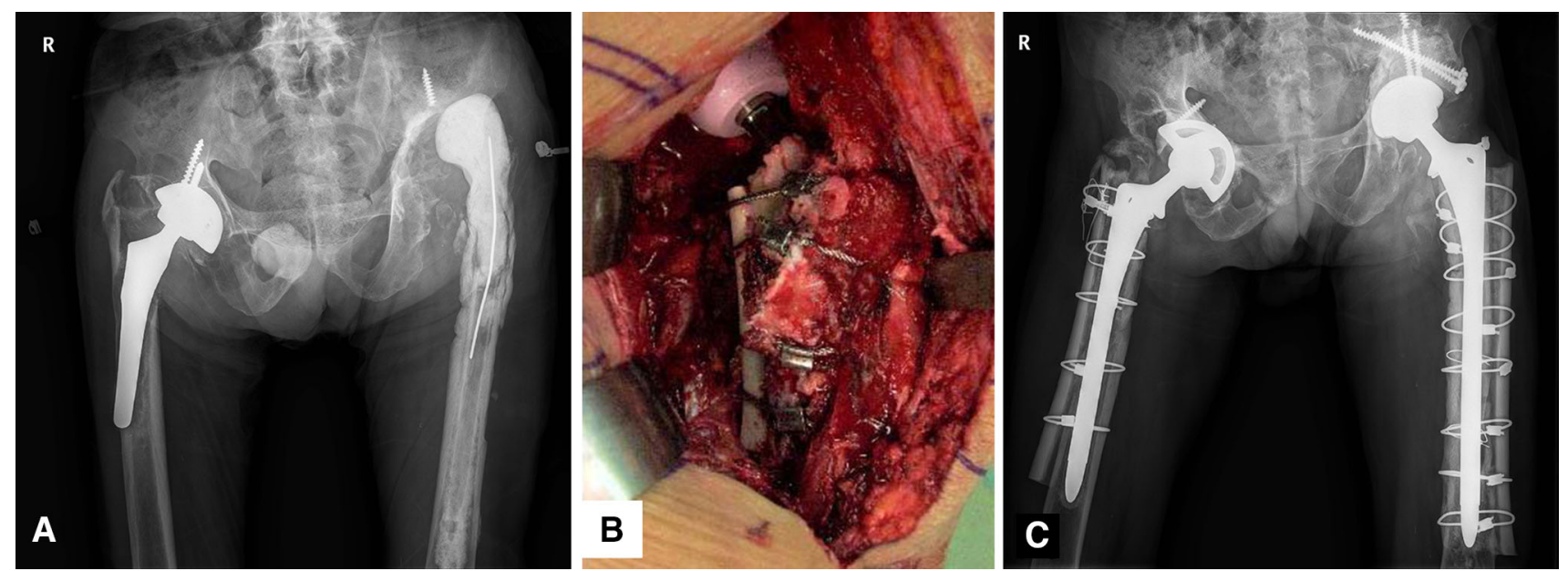

Fig. 1A-C A 45-year-old man had Paprosky Type IV bone defects of both hips. (A) His AP radiograph shows a loose porous-coated anatomic cementless femoral component and dislocated cement spacer of the left hip before revision surgery. (B) An intraoperative photographs shows the allografts are fixed with four Dall-Miles ${ }^{\mathrm{TM}}$

The allografts were secured to the host bone with an average of five cables (range, 4-8 cables). Definitive intraoperative stability of the implants was achieved by complete tightening of the cortical strut onlay allografts. Supplemental cancellous bone grafts around the strut grafts were applied in all patients. Vascularized muscle tissue was placed over all of the grafts. For all cases, long extensively porous-coated cementless femoral prostheses were used (Solution System ${ }^{\mathbb{R}}$; DePuy). The mean diameter of Solution System ${ }^{\circledR}$ stem was $17.25 \mathrm{~mm}$ (range, $15-19.5 \mathrm{~mm}$ ) (Fig. 1). Alternatives such as allograft-prosthesis composites, modular fluted, tapered stems were not used, because these stems did not appear to be able to be fixed in the damaged diaphyseal-isthmic bone.

All of the patients began standing at the bedside or walking with assistance of crutches or a walker twice daily for 30 minutes each time under the supervision of a therapist on the second postoperative day. The patients used crutches or a walker with toe-touch weightbearing for 3 months and used a cane with full weightbearing when needed thereafter.

The interpretation of all radiographs was done in a blinded fashion by one observer (JWP) who was not involved in treatment of any of the patients. Implant subsidence was measured using constant reference points for each patient such as a tip of the greater trochanter and the upper margin of the shoulder of the prosthesis [33]. The radiographic stability was classified according to the techniques of Engh and Massin [12].

The radiographic criterion of incorporation of cortical strut onlay allograft to host bone was complete bridging
(Stryker Orthopaedics, Mahwah, NJ, USA) cables. (C) An AP radiograph of both hips taken 2 weeks after revision surgery shows the femoral and acetabular components are well fixed in a satisfactory position. The allografts are attached to the host bone with DallMiles $^{\mathrm{TM}}$ cables.

between strut allograft and host bone. The allograft was divided into modified Gruen zones [13]. Resorption of cortical strut onlay allograft was graded as follows [24]: mild, less than $50 \%$ of allograft thickness in one or two zones; moderate, less than $50 \%$ of thickness of allograft in more than two zones or greater than $50 \%$ of thickness but not fully thickness in one or two zones; or severe, full thickness in any zone or greater than $50 \%$ of thickness in more than two zones. Data from all radiographs showed that for angular measurements, the mean intraobserver difference was $1.5^{\circ}$ (range, $0.8^{\circ}-2.5^{\circ}$ ) and the intraclass correlation coefficient was 0.95 . For linear measurements (width of radiolucent line and resorption of allograft), the mean intraobserver difference was $1.5 \mathrm{~mm}$ (range, 1.0 $1.8 \mathrm{~mm}$ ) and the intraclass correlation coefficient was 0.96 .

\section{Statistical Analysis}

Descriptive analysis was performed using the mean and frequency for continuous and categorical variables, respectively. Cumulative survival rates and associated $95 \%$ CIs were calculated using a Kaplan-Meier survival curve [22]. Comparisons of clinical characteristics and preoperative and postoperative values used ANOVA for continuous variables or chi-square test or Fisher's exact test for categorical variables. Statistical analysis was performed using SPSS software (Version 19.0; IBM, Armonk, NY, USA), and a p value less than 0.05 was considered significant. 


\section{Results}

Preoperative outcome scores were improved significantly $(p=0.002)$ after revision surgery. The Harris hip scores improved from a mean of $39 \pm 10$ points (range, 21-54 points) before revision surgery to a mean of $86 \pm 14$ points (range, 50-92 points) at the latest followup. Mean improvement was 47 points (95\% CI, 39.1-52.3 points) $(\mathrm{p}=0.002)$. Before revision surgery, the mean pain score was 14 points (range, 9-19 points) and the mean function score was 25 points (range, $12-35$ points). At the latest followup, the mean pain score was 42 points (range, 26-44 points) and the mean function score was 44 points (range, 24-48 points) $(p=0.002)$. Limping, dependence on a walking aid, and walking distance were improved markedly after revision surgery $(\mathrm{p}=0.004)$. The WOMAC score improved from a mean of $62 \pm 29$ points before revision surgery to a mean of $22 \pm 19$ points at followup. Mean improvement was 40 points (30-40 points) (95\% CI, 36.5-44.1) $(\mathrm{p}=0.003)$ (Table 2).

Table 2. Clinical results

\begin{tabular}{|c|c|c|c|c|}
\hline Parameters & Before revision surgery & Final followup (16.1 years) & Improvement & p Value (ANOVA) \\
\hline $\begin{array}{l}\text { Total Harris } \\
\text { hip score (points)* }\end{array}$ & Mean $39 \pm 10(21-54)$ & Mean $86 \pm 14(50-92)$ & $\begin{array}{l}\text { Mean } 47(29-38) \\
{[39.1-52.3]}\end{array}$ & 0.002 \\
\hline Pain score & Mean 14 (9-19) & Mean $42(26-44)$ & $28(17-25)$ & \\
\hline Function score & Mean 25 (12-35) & Mean 44 (24-48) & $19(12-13)$ & \\
\hline \multicolumn{5}{|l|}{ Degree of pain } \\
\hline None & 0 & 40 patients $(33 \%)$ & & $<0.001$ \\
\hline Slight & 0 & 32 patients $(27 \%)$ & & \\
\hline Mild & 0 & 28 patients $(23 \%)$ & & \\
\hline Moderate & 85 patients $(71 \%)$ & 9 patients $(8 \%)$ & & \\
\hline Marked & 35 patients $(29 \%)$ & 11 patients $(9 \%)$ & & \\
\hline Totally disabled & 0 & 0 & & \\
\hline \multicolumn{5}{|l|}{ Limp } \\
\hline None & 0 & 30 patients $(25 \%)$ & & 0.004 \\
\hline Slight & 0 & 42 patients $(35 \%)$ & & \\
\hline Moderate & 85 patients $(71 \%)$ & 37 patients $(31 \%)$ & & \\
\hline Severe & 35 patients $(29 \%)$ & 11 patients $(9 \%)$ & & \\
\hline Unable to walk & 0 & 0 & & \\
\hline \multicolumn{5}{|l|}{ Support } \\
\hline None & 0 & 87 patients $(72 \%)$ & & 0.004 \\
\hline Cane, long walks & 0 & 13 patients $(11 \%)$ & & \\
\hline Cane, full time & 60 patients $(50 \%)$ & 9 patients $(8 \%)$ & & \\
\hline 1 crutch & 7 patients $(6 \%)$ & 0 & & \\
\hline 2 crutches & 53 patients $(44 \%)$ & 11 patients $(9 \%)$ & & \\
\hline Unable to walk & 0 & 0 & & \\
\hline \multicolumn{5}{|l|}{ Distance walked } \\
\hline Unlimited & 0 & 40 patients $(33 \%)$ & & 0.004 \\
\hline 6 blocks & 0 & 60 patients $(50 \%)$ & & \\
\hline 2-3 blocks & 85 patients $(71 \%)$ & 9 patients $(8 \%)$ & & \\
\hline Indoors only & 35 patients $(29 \%)$ & 11 patients $(9 \%)$ & & \\
\hline Bed and chair & 0 & 0 & & \\
\hline \multicolumn{5}{|l|}{ WOMAC score } \\
\hline Total & Mean $62.9 \pm 29(41-91)$ & Mean $22 \pm 19(11-51)$ & Mean $40(30-40)$ & 0.003 \\
\hline \multicolumn{5}{|l|}{ Satisfaction } \\
\hline Fully satisfied & $0(0 \%)$ & 40 patients $(33 \%)$ & & \\
\hline Satisfied & $0(0 \%)$ & 60 patients $(50 \%)$ & & \\
\hline Somewhat dissatisfied & $0(0 \%)$ & 9 patients $(8 \%)$ & & \\
\hline Fully dissatisfied & 130 patients $(100 \%)$ & 11 patients $(9 \%)$ & & \\
\hline
\end{tabular}

* Ranges in parentheses. 95\% CI in brackets. 
Of the 130 stems, 113 (87\%) had bone ingrowth, five (4\%) had stable fibrous ingrowth, and 12 (9\%) were unstable. Eleven of 12 stems were revised or rererevised with a larger cementless Solution System ${ }^{\circledR}$ stem and one hip was rerevised with the largest Wagner stem (Zimmer, Warsaw, IN, USA) on the market. In this particular case, the largest Solution System ${ }^{\circledR}$ stem was not able to provide axial and torsional stability; therefore, the largest Wagner stem was used to provide axial and torsional stability (Fig. 2). We did not detect bone resorption of the proximal host femur related to stress shielding in the current series, because the proximal host femur was covered by cortical strut allograft. Allografts were incorporated in the host femur consistently and reliably by 1 year, on average, in all hips. Although bone ingrowth cannot occur from a cortical strut allograft to a porous-coated stem (because the cortical strut allograft has no vital cells), there was no intervening radiolucent line at the interface between the cortical strut allograft and the host bone in 120 hips (92\%). In the remaining 10 hips, there was a radiolucent line smaller than $1 \mathrm{~mm}$ between the host bone and allograft. There was slight loss of length of the cortical strut onlay allografts by remodeling at the ends of the allografts. The resorption of allografts was graded as mild in 110 hips $(85 \%)$ and moderate in 20 hips (15\%). The resorption of allograft was noticed 1 year after revision and it progressed slowly. The resorption usually abated by 3 years. Minor resorption of the allograft was seen around cables, but there were no failures of any of the cortical strut onlay allografts (Table 3). The previous allografts provided enhanced bone stock in all hips.
Four hips (3\%) had a displaced femoral shaft fracture at the stem tip after revision surgery. The fractures were fixed with two bivalve femoral cortical strut onlay grafts and healed uneventfully. The femoral stems were stabilized by bone ingrowth at the latest followup.

Six hips (5\%) had an early postoperative infection. In four of the six hips, the infections were treated successfully

Table 3. Radiographic results at final followup

\begin{tabular}{ll}
\hline Parameters & Numbers \\
\hline Fixation of stem & \\
Bone ingrowth stable fibrous & 113 hips $(87 \%)$ \\
Ingrowth & 5 hips $(4 \%)$ \\
Unstable & 12 hips $(9 \%)$ \\
Union of allograft & 130 hips $(100 \%)$ \\
Length of allograft (cm) & \\
Medial cortical strut* & \\
$\quad$ Initial & $13 \mathrm{~cm}(10-20 \mathrm{~cm})$ \\
$\quad$ Final & $12 \mathrm{~cm}(8-18 \mathrm{~cm})$ \\
Lateral cortical strut* & \\
$\quad$ Initial & $13 \mathrm{~cm}(9-18 \mathrm{~cm})$ \\
$\quad$ Final & $11 \mathrm{~cm}(8-17 \mathrm{~cm})$ \\
Posterior cortical strut* & \\
Initial & $11 \mathrm{~cm}(9-13 \mathrm{~cm})$ \\
$\quad$ Final & $10 \mathrm{~cm}(9-13 \mathrm{~cm})$ \\
Resorption of allograft & \\
Mild & 110 hips $(85 \%)$ \\
Moderate & 20 hips $(15 \%)$ \\
\hline
\end{tabular}

* Ranges in parentheses.
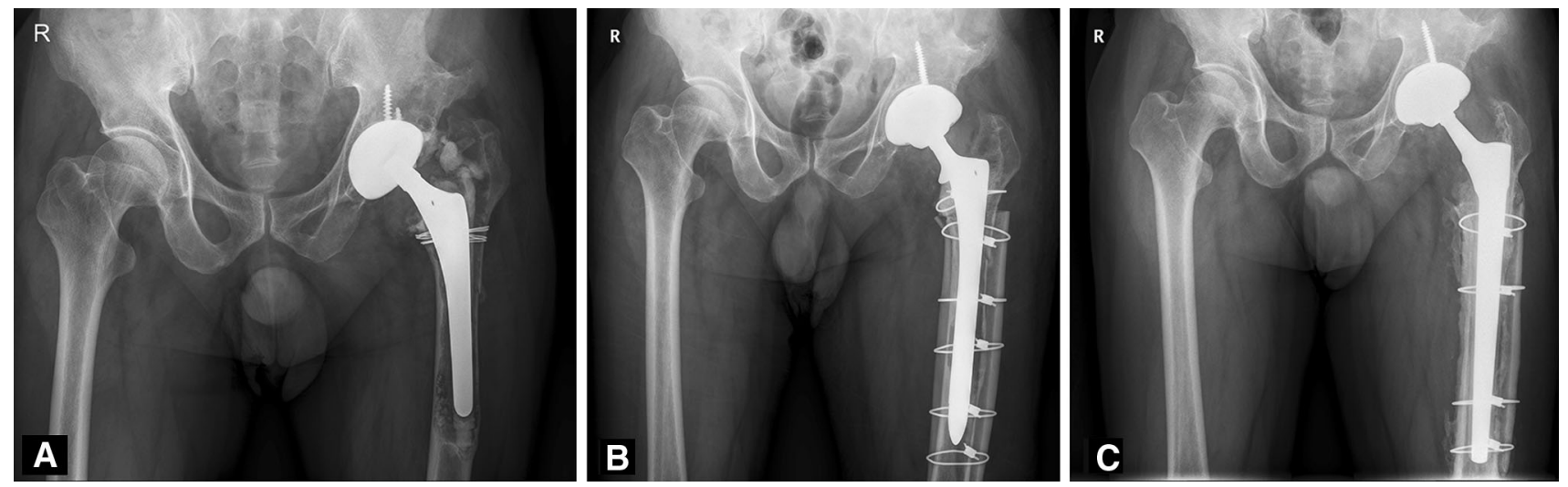

Fig. 2A-C A 65-year-old man had aseptic loosening of the cemented femoral component. (A) His prerevision AP radiograph shows a cement fracture, varus shift, and subsidence of the left femoral component. The bone defect of the left femur is Paprosky Type IV. (B) An AP radiograph of the patient's left hip taken 6 months after surgery shows a fully porous-coated cementless stem and two strut cortical onlay allografts placed in a satisfactory position. Although there is no radiographic loosening of the femoral component, the patient reported severe pain during weightbearing. This patient had the largest size of Solution System ${ }^{\circledR}$ stem implanted during revision surgery, but he had persistent pain and underwent rerevision surgery using the largest size Wagner stem. (C) The AP radiograph taken 15 years after rerevision surgery shows the Wagner cementless stem is embedded in a satisfactory position with solid bone ongrowth on the entire femoral stem. A two-cortical strut onlay allograft was incorporated in the host bone. The acetabular component is well fixed in a satisfactory position. 
by open débridement and 6 weeks of intravenous antibiotics. The remaining two hips with failed open débridement underwent two-stage exchange arthroplasty. None of these hips had recurrence of infection. Four hips $(3 \%)$ had a postoperative dislocation and these were treated by closed reduction and an abduction brace for 3 months. There were no additional dislocations. Five hips (4\%) had calf thrombi but there were no pulmonary embolisms after treatment with a mechanical compression device. No patient had wound problems. No hip had Grade III or IV heterotopic ossification [7].

Kaplan-Meier survival analysis revealed $91 \%$ survivorship of the femoral components as the endpoint of revision or aseptic loosening at 16 years (95\% CI, 0.88-0.96). In the worst-case scenario, Kaplan-Meier survivorship analysis, with revision or mechanical failure as the end point for failure, estimated the 16-year survival rate of the femoral component to be $83 \%$ ( $95 \%$ CI, 0.78-0.88), if the 10 patients who did not complete followup or died were assumed to have a failed femoral component. Twelve hips (9\%) were revised owing to failure of femoral components. Ten of these 12 hips were rerevised for aseptic loosening, whereas two of the 12 hips were rerevised for an infection. Two of the 10 hips had three more rerevisions for aseptic loosening. In these 10 rerevised hips because of aseptic loosening, four had Paprosky Type IIIB and six had Type IV femoral diaphyseal bone defects.

\section{Discussion}

Numerous studies have investigated the clinical and radiographic results of revision THAs with the use of cementless stem and strut allografts $[10,11,15,19,22,23$, 27]. However, to our knowledge, no long-term followup studies have evaluated patients undergoing revision THA with use of cortical strut allografts where the allografts provided the primary stability for extensively coated femoral stems in the presence of extensive femoral diaphyseal bone defects. The purpose of our study was to determine (1) validated outcome scores; (2) radiographic signs of fixation and allograft healing; (3) frequency of complications; and (4) survivorship of the components after use of cortical strut onlay allografts in Paprosky Types IIIB and IV femoral diaphyseal bone defects.

There are some limitations to our study. First, two concerns common in retrospective and nonrandomized trials were unlikely to have been a factor here: selection bias and lost to followup. We treated $100 \%$ of our patients with Paprosky Types IIIB and IV femoral defects using this approach between 1994 and 2003; no patient was treated with another approach. We also were able to account for a large proportion of our patients at a minimum followup of
12 years. This is unusual in long-term studies of this sort, and gives us confidence that few patients could have undergone revision surgery elsewhere for undetected failures. Second, we have no interobserver variability to ensure interpreting hip scores and radiographic findings, including radiolucent line and loosening. However, the intraclass correlation coefficient for intraobserver difference in angular radiographic measurement was 0.95 and in linear radiographic measurement was 0.96 , indicating excellent reproducibility in these measurements. Finally, although all allografts appeared to be incorporated radiographically, radiographs are not reliable indicators of graft incorporation. Furthermore, radiolucent lines between the strut allograft and porous implant may be missed on simple AP and lateral views of radiographs.

Large bulk allografts, such as proximal femoral allografts or proximal femoral or total femoral replacement prostheses such as those used in tumor cases, have been proposed as suitable reconstructive techniques for more severe femoral defects $[6,9,10,29,32,33]$. To our knowledge, no long-term clinical results have been reported. Emersen et al. [11] reported that clinical results of femoral revision with strut allografting showed satisfactory results with an average Harris hip score of 79.6 points at average 34 months followup. Barden et al. [3] reported that clinical results of supportive strut grafts for diaphyseal bone defects in revision THAs in 20 patients showed the average Harris hip score was 75.7 points (range, 58-92 points) at mean 4.7 years followup. All of their patients were bedridden or wheelchair bound. They suggested that lower Harris hip score was a result of reduced abductor muscle function rather than pain. Head and Malinin [18] showed that the average Harris hip score improved 45 points at average 9.5 years followup in 251 patients who underwent revision THAs with strut allografts. In the current study, the average hip score improved 47 points at 16 years followup. Our clinical results showed satisfactory results compared with historic controls [3, 11, 18, 19, 25] despite much longer followup. We believe that all of the allografts united to the host bone, and relatively good function of the abductor muscle resulted in satisfactory outcomes.

Barden et al. [3] reported that 17 of 20 cementless femoral revision stems radiographically showed bone ingrowth. Three of 20 revision femoral stems were interpreted as being fixed only by fibrous ingrowth after early subsidence. Head and Malinin [18] reported that $97 \%$ of revision THAs with strut allografts had stable fixation with bone ingrowth at an average of 9.5 years followup. However, Emerson et al. [11] reported that eight stems (7\%) subsided greater than $1 \mathrm{~cm}$, all of which were clinical failures. In the current study, $91 \%$ of femoral stems (118 of 130 stems) had stable fixation at a mean followup of 


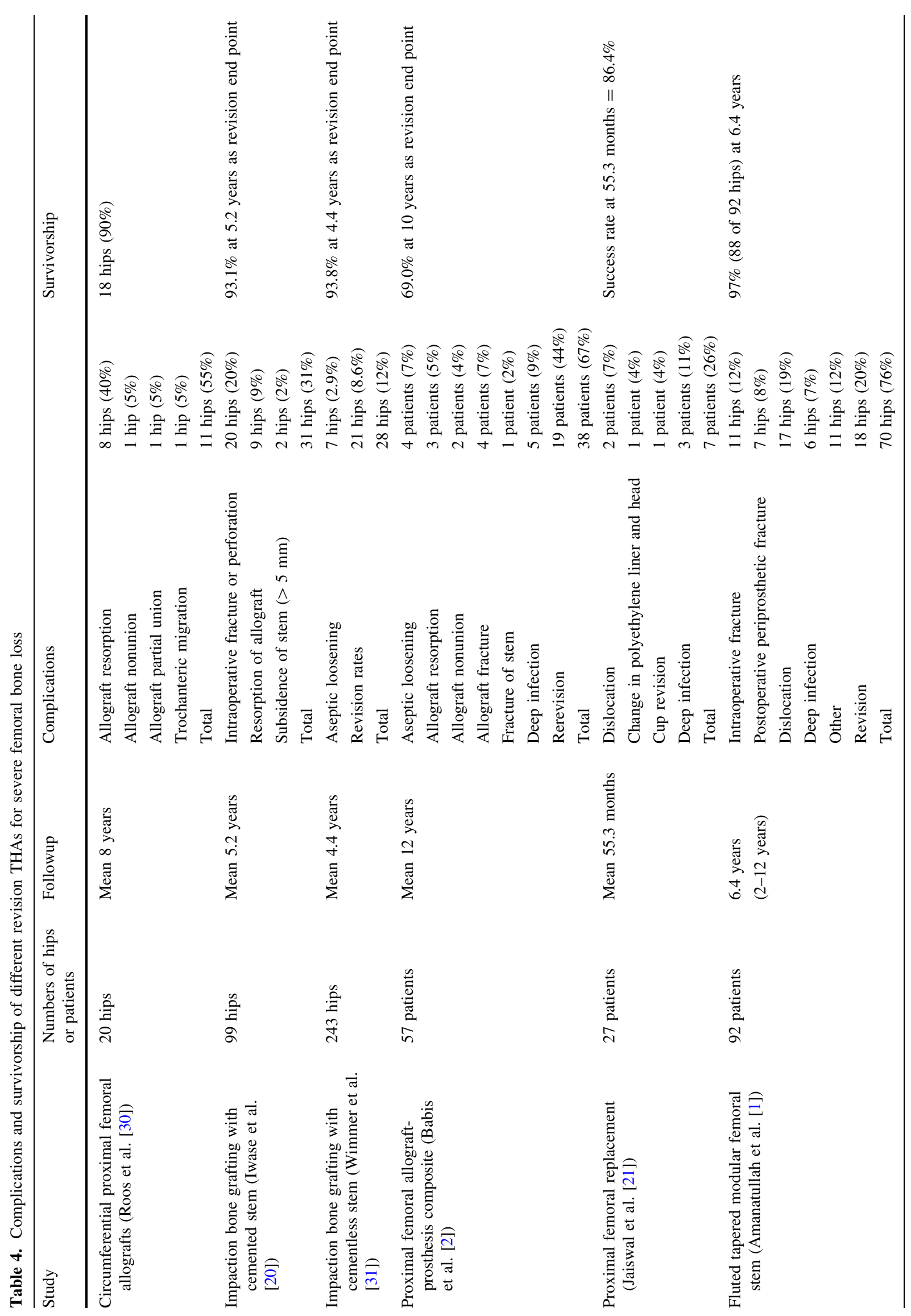




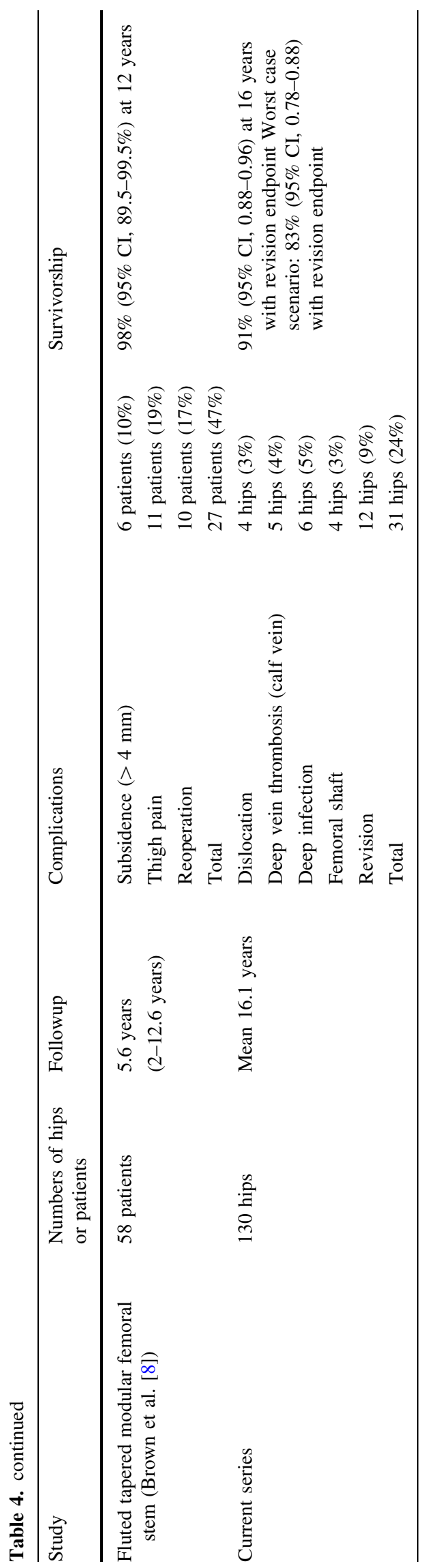

16 years. Our results compared well with the results of other series with a short-term followup [11, 18, 19, 25, 27].

A low incidence of failed cortical strut onlay allograft incorporation ranging from $0 \%$ to $7 \%$ has been reported $[10,12,18,27,33]$. These results appear to be confirmed by the apparent incorporation of the cortical strut onlay allografts in the current study. Only small amounts of allograft resorption were observed in all hips. There were no cases of major resorption of the cortical strut allografts used in this study. Buoncristiani et al. [9] found diminution of allografts in $38 \%$ of cases, and in one of 32 cases, the allograft appeared to have resorbed completely. In the series of Pak et al. [27], the strut allografts showed severe resorption around femoral stems (7\%). Haddad et al. [15] noted a higher rate of resorption $(28 \% ; 11$ of 40 cases) of the allografts. They also reported that severe resorption of allograft was observed only in cases in which the proximal host femur was discarded for proximal segmental structural allografting [14]. They generated a hypothesis regarding its potential etiology, and the discarded proximal host femur may play a role [15]. The residual host bone may have a physical and immune-protective effect that was not present in their cases. Hamadouche et al. [16] also suggested that when a structural cortical strut allograft is used during revision THA, the host femur should be retained to enhance allograft incorporation. In the current series, the apparent biologic incorporation of all cortical strut onlay allografts could be attributed to the large contact area between the allografts and the host bone [12] and the retained host femur [14]. Although there was no apparent stress shielding in the proximal femur in our series, stress shielding would appear with longer-term followup, because load bearing is transferred more distal to the femur by a fully porouscoated stem. Barden et al. [3] reported one case of peroneal nerve palsy, one case of deep vein thrombosis (DVT), and one case of pneumonia. They had no dislocation of revision THAs. However, Pak et al. [27] reported a 7\% dislocation rate (eight of 113 hips). In our series, there were low incidences of DVT and dislocation. We believe that a mechanical compression device for DVT treatment decreased the incidence of DVT. Good alignment of the components and good abductor muscle function were attributed to the low dislocation rate.

The infection rate after revision THA using cortical strut allografts has been reported to range between $0 \%$ and $2 \%$ $[3,6,10,12,27]$. The high postoperative deep infection rate $(5 \%)$ in our series can be explained by multiple previous surgeries that patients had undergone, long operative time, and the large size of cortical strut onlay allografts. Complication and reoperation rates of alternative techniques, including circumferential proximal femoral allograft [30], impaction bone grafting [20, 31], proximal femoral allograft-prosthesis composites [2], proximal 
femur replacements [21], and modular fluted tapered stems $[1,8]$ appear to be greater than in the current study despite that the durations of followup were substantially shorter in those series (Table 4).

Head and Malinin [18] reported the survival rate of revision cementless stems with structural onlay allografts was $97 \%$ at 9.5 years followup. Barnes et al. [3] reported the survival rate of revision THA with strut allografts was $100 \%$ at 4.7 years followup. Emerson et al. [11] reported the survival rate for revision cementless stems with cortical strut allografts was $93 \%$ at 8.4 months followup. They suggested that revision femoral component stability and clinical success was attributable to a combination of implant design, surgical technique, and host-bone factors. In the current series, survivorship of the revision stem was $91 \%$ and in the worst-case scenario, it was $83 \%$. We believe that rigid distal fixation of extensively porous-coated long femoral stems with femoral strut allografts was attributable to good results.

Supportive cortical strut onlay allografts provided high survivorship beyond 12 years of followup in revision THAs. Further studies might compare this approach with allograft-prosthesis composites, proximal femoral replacements, or modular fluted, tapered stems.

Acknowledgments We thank Doo-Ri Kim BA (The Joint Replacement Center, Ewha Womans University School of, Medicine, Seoul, Republic of Korea) for review of clinical and radiographic data.

\section{References}

1. Amanatullah DF, Howard JL, Siman H, Trousdale RT, Mabry TM, Berry DJ. Revision total hip arthroplasty in patients with extensive proximal femoral bone loss using a fluted tapered modular femoral component. Bone Joint J. 2015;97:312-317.

2. Babis GC, Sakellariou VI, O'Connor MI, Hanssen AD, Sim FH. Proximal femoral allograft-prosthesis composites in revision hip replacement: a 12-year follow-up study. J Bone Joint Surg Br. 2010;92:349-355.

3. Barden B, Fitzek JG, Huttegger C, Löer F. Supportive strut grafts for diaphyseal bone defects in revision hip arthroplasty. Clin Orthop Relat Res. 2001;387:148-155.

4. Barrack RL, McClure JT, Burak CF, Clohisy JC, Parvizi J, Hozack W. Revision total hip arthroplasty: the patient's perspective. Clin Orthop Relat Res. 2006;453:173-177.

5. Bellamy N, Buchanan WW, Goldsmith CH, Campbell J, Stitt LW. Validation study of WOMAC: a health status instrument for measuring clinically important patient relevant outcomes to antirheumatic drug therapy in patients with osteoarthritis of the hip or knee. J Rheumatol. 1988;15:1833-1840.

6. Bono JV, McCarthy JC, Lee J, Carangelo RJ, Turner RH. Fixation with a modular stem in revision hip arthroplasty. Instr Course Lect. 2000;49:131-139.

7. Brooker AF, Bowerman JW, Robinson RA, Riley LH Jr. Ectopic ossification following total hip replacement: incidence and method of classification. J Bone Joint Surg Am. 1973:55:1629-1632.
8. Brown NM, Tetreault M, Cipriano CA, Della Valle CJ, Paprosky W, Sporer S. Modular tapered implants for severe femoral bone loss in THA: reliable osseointegration but frequent complications. Clin Orthop Relat Res. 2015;473:555-560.

9. Buoncristiani AM, Dorr LD, Johnson C, Wan Z. Cementless revision of total hip arthroplasty using the anatomic porous replacement revision prosthesis. J Arthroplasty. 1997;12:403-415.

10. Duncan CP, Masri BA. Fractures of the femur after hip replacement. Instr Course Lect. 1995;44:293-304.

11. Emerson RH Jr, Malinin TI, Cuellar AD, Head WC, Peters PC. Cortical strut allografts in the reconstruction of the femur in revision total hip arthroplasty: a basic science and clinical study. Clin Orthop Relat Res. 1992;285:35-44.

12. Engh CA, Massin P. Cementless total hip arthroplasty using the anatomic medullary locking stem: results using a survivorship analysis. Clin Orthop Relat Res. 1989;249:141-158.

13. Gruen TA, McNeice GM, Amstutz HC. "Modes of failure" of cemented stem-type femoral components: a radiographic analysis of loosening. Clin Orthop Relat Res. 1979;141:17-27.

14. Haddad FS, Garbuz DS, Masri BA, Duncan CP. Structural proximal femoral allografts for failed total hip replacements: a minimum review of five years. J Bone Joint Surg Br. 2000;82:830-836.

15. Haddad FS, Masri BA, Garbuz DS, Duncan CP. Femoral bone loss in total hip arthroplasty: classification and preoperative planning. Instr Course Lect. 2000;49:83-96.

16. Hamadouche M, Blanchat C, Meunier A, Kerboull L, Kerboull M. Histological findings in a proximal femoral structural allograft ten years following revision total hip arthroplasty: a case report. $J$ Bone Joint Surg Am. 2002;84:269-273.

17. Harris WH. Traumatic arthritis of the hip after dislocation and acetabular fractures: treatment by mold arthroplasty. An end-result study using a new method of result evaluation. J Bone Joint Surg Am. 1969;51:737-755.

18. Head WC, Malinin TI. Results of onlay allografts. Clin Orthop Relat Res. 2000;371:108-112.

19. Head WC, Malinin TI, Mallory TH, Emerson RH Jr. Onlay cortical allografting for the femur. Orthop Clin North Am. 1998;29:307-312.

20. Iwase T, Otsuka H, Katayama N, Fujita H. Impaction bone grafting for femoral revision hip arthroplasty with Exeter Universal stem in Japan. Arch Orthop Trauma Surg. 2012;132:1487-1494.

21. Jaiswal PK, Jagiello J, David LA, Blunn G, Carrington RW, Skinner JA, Cannon SR, Briggs TW. Use of an 'internal proximal femoral replacement' with distal fixation in revision arthroplasty of the hip. J Bone Joint Surg Br. 2008;90:11-15.

22. Kaplan EL, Meier P. Nonparametic estimation from incomplete observations. J Am Stat Assoc. 1958;53:457-481.

23. Kim YH. Cementless revision hip arthroplasty using strut allografts and primary cementless proximal porous-coated prosthesis. J Arthroplasty. 2004;19:573-581.

24. Kim YH, Franks DJ. Cementless revision of cemented stem failures associated with massive femoral bone loss: a technical note. Orthop Rev. 1992;21:375-380.

25. Kim YH, Kim JS. Revision hip arthroplasty using strut allografts and fully porous-coated stems. J Arthroplasty. 2005;20:454-459.

26. Lewallen DG, Berry DJ. Periprosthetic fracture of the femur after total hip arthroplasty: treatment and results to date. Instr Course Lect. 1998;47:243-249.

27. Pak JH, Paprosky WG, Jablonsky WS, Lawrence JM. Femoral strut allografts in cementless revision total hip arthroplasty. Clin Orthop Relat Res. 1993;295:172-178.

28. Paprosky WG, Greidanus NV, Antoniou J. Minimum 10-year results of extensively porous-coated stems in revision hip arthroplasty. Clin Orthop Relat Res. 1999;369:230-242. 
29. Steinbrink K, Engelbrecht E, Fenelon GC. The total femoral prosthesis: a preliminary report. J Bone Joint Surg Br. 1982; 64:305-312.

30. Roos BD, Roos MV, Camisa A Jr. Circumferential proximal femoral allografts in revision hip arthropalsty: four to 20 years follow-up. Hip Int. 2013;23:66-71.

31. Wimmer MD, Randau TM, Demi MC, Ascherl R, Nöth U, Forst T, Gravius N, Wirtz D, Gravius S. Impaction grafting in the femur in cementless modular revision total hip arthroplasty: a descriptive outcome analysis of 243 cases with the MRP-TITAN revision implant. BMC Musculoskelet Disord. 2013;14:19.

32. Wong P, Gross AE. The use of structural allografts for treating periprosthetic fractures about the hip and knee. Orthop Clin North Am. 1999;30:259-264.

33. Zmolek JC, Dorr LD. Revision total hip arthroplasty: the use of solid allograft. J Arthroplasty. 1993;8:361-370. 